\title{
Estudo comparativo da eficácia do uso de prednisolona e cetorolaco de trometamina tópicos após cirurgia de
}

estrabismo

Comparison of the efficacy of topical prednisolone and Ketorolac tromethamine after
strabismus surgery

$\begin{array}{lc}\text { Jorge } & \text { Meireles-Teixeira } \\ \text { Marcos } & \text { Pitarello Moya } \\ \text { Jairo } & \text { Cuperman } \\ \text { Tomás } & \text { Mendonça } \\ \text { Célia } & \text { Nakanami }\end{array}$

Trabalho desenvolvido no setor de motilidade ocular extrínseca, do Departamento de Oftalmologia da Universidade Federal de São Paulo - UNIFESP.

Pós-graduando do setor de Motilidade Ocular Extrínseca do Departamento de Oftalmologia da Universidade Federal de São Paulo - UNIFESP.

${ }^{2}$ Estagiário do $2^{\circ}$ ano do setor de Motilidade Ocular Extrínseca do Departamento de Oftalmologia da Universidade Federal de São Paulo - UNIFESP;

${ }^{3}$ Colaborador do setor de Motilidade Ocular Extrínseca do Departamento de Oftalmologia da Universidade Federal de São Paulo - UNIFESP;

${ }^{4}$ Chefe do setor de Motilidade Ocular Extrínseca do Departamento de Oftalmologia da Universidade Federal de São Paulo - UNIFESP.

Endereço para correspondência: Rua Cumã,12 - Apt. 201 - São Luís (MA) CEP 04511-001

E-mail: jorgemeireles@bol.com.br

Recebido para publicação em 22.03.2002

Aceito para publicação em 07.10.2002

\section{RES UMO}

Objetivo: Avaliar os resultados do uso de antiinflamatório não hormonal (AINH) no controle da inflamação no pós-operatório de estrabismo, comparando-se com corticóide tópico. Métodos: Selecionaram-se exclusivamente pacientes submetidos a recuo-ressecção em um só olho. Os dois grupos de pacientes usaram o mesmo antibiótico, sendo que para um grupo foi prescrito prednisolona $0,12 \%$ e para o outro cetorolaco de trometamina. Eles foram avaliados quanto a hiperemia, edema, conforto e variação da pressão intra-ocular, até o $21^{\circ}$ dia de pós-operatório. Resultados: Foram 27 pacientes, sendo 15 no grupo de AINH e 12 no de corticóide. Com relação a edema, conforto e PIO não houve variação entre os grupos. Porém, no grupo com AINH houve 5 (33,3\%) casos de hiperemia conjuntival de $++/ 4$ no $21^{\circ}$ dia de pós-operatório e três $(20 \%)$ de granuloma. Entre os pacientes com corticóide só se observou $1(8,3 \%)$ caso de hiperemia de $++/ 4$ ao término do tratamento e nenhum de granuloma. Conclusão: Para cirurgias de recuo-ressecção, procedimentos que parecem induzir maior resposta inflamatória, o uso de AINH não é aconselhável.

Descritores: Inflamação/quimioterapia; Estrabismo/cirurgia; Antiinflamatórios esteróides/ uso terapêutico; Prednisolona tópica/uso terapêutico; Cetorolaco de trometamina/uso terapêutico; Estudo comparativo; Eficácia de tratamento

INTRODUÇ̃̃O

É rotina utilizar-se corticóide tópico no período pós-operatório de cirurgias oftalmológicas, dentre elas as de estrabismo, com o intuito de se controlar a resposta inflamatória ${ }^{(1)}$. Normalmente estas drogas são associadas a antibióticos, muito embora ainda haja controvérsias quanto à necessidade ou não do uso destes últimos no pós-operatório de estrabismo ${ }^{(2-4)}$.

Os corticóides controlam a resposta inflamatória inibindo as duas vias de formação das suas substâncias mediadoras. Os fosfolipídios das membranas celulares lesadas, através da enzima fosfolipase $2 \alpha$ são convertidos a ácido aracdônico, que é o substrato comum de ambas as vias de formação dos mediadores da resposta inflamatória: a da cicloxigenase, que o transforma em prostaglandinas e a da lipoxigenase, que o converte a hidroxilas e leucotrienos ${ }^{(5)}$. As drogas antiinflamatórias não hormonais (AINH) agem apenas na via da cicloxigenase, uma etapa mais tardia da formação destas substâncias mediadoras e graças a isto, não interferem na cicatrização das feridas, como os corticóides, que alteram a síntese do colágeno ${ }^{(1)}$. 
Alguns estudos mostram as vantagens do uso dos AINH no controle do processo inflamatório após cirurgia oftalmológica. Com os AINH os pacientes tendem a se sentir mais confortáveis, devido ao efeito analgésico destas drogas. Além disso, o uso de AINH evita certas complicações, como o surgimento de infecções (principalmente a recorrência de herpes), glaucoma secundário (ou apenas elevação temporária da pressão ocular, efeito notado principalmente em crianças), catarata e retardo na cicatrização da ferida operatória ${ }^{(1,5-7)}$. O único efeito colateral observado relacionado ao uso dos AINH foi a presença de hemorragia subconjuntival em alguns pacientes. É sabido que o uso sistêmico de AINH pode levar à deficiência na agregação das plaquetas e aumentar o tempo de sangramento, porém, não há comprovação científica que o uso tópico de AINH possa propiciar sangramento intra-ocular no período pós-operatório ${ }^{(5-6)}$.

Alguns trabalhos revelam as vantagens do uso de AINH para o controle da inflamação após cirurgia de estrabismo. Estes autores avaliaram predominantemente pacientes submetidos a duplo recuo de retos ${ }^{(1,6)}$.

Considerando-se que a cirurgia simétrica (duplo recuo de retos horizontais) parece induzir menor resposta inflamatória que a cirurgia de recuo-ressecção, pelo menor trauma que causa, neste estudo optou-se por se avaliar os efeitos do uso de corticóide ou AINH apenas em pacientes submetidos a recuo-ressecção de retos horizontais; a fim de se observar se os AINH seriam tão eficazes quanto os corticóides, para o controle da inflamação, nestes casos onde ela se faz mais intensa.

\section{MÉTODOS}

Foram selecionados 27 pacientes com idades variando de 17 a 48 anos (media de 35,8 anos), sem história prévia de cirurgia ocular ou trauma, de inflamação ocular ou de hipersensibilidade às drogas empregadas; que se submeteram a recuoressecção de retos horizontais em um só olho, sob anestesia tópica, utilizando-se como fio de sutura a poligalactina - Vycril $^{\circledR}$ 6-0 (inclusive na conjuntiva), para tratamento de esotropia ou exotropia, sempre pelo mesmo cirurgião. Todos os pacientes assinaram termo de consentimento, autorizando sua participação na pesquisa.

Para anestesia utilizou-se a aplicação de xilocaína sob a forma de gel, cerca de 2 minutos antes da cirurgia. No momento da cirurgia o gel foi removido pela irrigação do olho com soro fisiológico $0,9 \%$ e foi feita injeção subconjuntival de 0,1 a $0,2 \mathrm{ml}$ de xilocaína $2 \%$ injetável com vasoconstritor, na conjuntiva adjacente à região a ser operada. Todas as incisões foram limbares.

No período pós-operatório os pacientes usaram o mesmo antibiótico - cloridrato de ciprofloxacina $\left(\right.$ Biamotil $\left.^{\circledR}\right)$ associado à prednisolona $0,12 \%\left(\right.$ Pred Mild $\left.^{\circledR}\right)$ ou cetorolaco de trometamina $0,5 \%\left(\right.$ Acular $\left.^{\circledR}\right)$. Nas associações antibiótico-corticóide usualmente prescritas para o controle inflamatório após cirur- gia de estrabismo a concentração deste último é de $0,10 \%$. Assim, o Pred Mild ${ }^{\circledR}$ (prednisolona 0,12\%) foi escolhido, por ser semelhante quanto à concentração da droga.

Eles foram separados aleatoriamente para entrar num ou noutro grupo (de corticóide ou AINH) e o estudo foi conduzido sem que o examinador e o paciente soubessem o colírio utilizado. As medicações foram usadas na $1^{\mathrm{a}}$ semana $4 \mathrm{x} / \mathrm{dia}$, depois $2 \mathrm{x} /$ dia por mais 2 semanas e então foram suspensas.

A avaliação foi feita sempre por um mesmo examinador, no $1^{\circ}, 7^{\circ}$ e $21^{\circ}$ dia de período pós-operatório, quanto à dor/ conforto (dado subjetivo feito com base na nota dada pelo paciente, numa escala de zero a 10 , sendo o valor atribuído inversamente proporcional ao desconforto) e quanto ao edema e hiperemia conjuntival (escala de $0 \mathrm{a}++++/ 4$ ) pela ectoscopia e biomicroscopia. Também foi medida a pressão intra-ocular (PIO) em ambos os olhos.

Para que não houvesse problemas com o custo das medicações elas foram doadas. Os pacientes que referiram não ter usado a medicação corretamente foram excluídos do estudo. Aqueles que não retornaram à época prevista ou que apresentaram algum outro problema no decorrer do período de avaliação, também foram retirados.

\section{RESULTADOS E DISCUSSÃO}

De um total de 27 pacientes, 15 foram tratados com AINH e 12 com corticóide (um paciente foi desprezado por apresentar conjuntivite viral). Optou-se por se usar o antibiótico separadamente e não associado ao corticóide ou AINH, para que desta forma os grupos variassem entre si apenas pela droga antiinflamatória empregada.

A média de recuo entre os pacientes que usaram corticóide foi de $6,8 \mathrm{~mm}(6,0$ a 7,5 mm) e a de ressecção de $6,6 \mathrm{~mm}(3,0$ a $8,5 \mathrm{~mm})$. No grupo com AINH a média do recuo foi da ordem de $6,9(5,0$ a $8,5 \mathrm{~mm})$ e a de ressecção de $6,7 \mathrm{~mm}(6,0$ a 7,0 $\mathrm{mm})$.

Considerando-se o conforto, edema e PIO, não se observou diferença importante entre os dois grupos. A média de PIO no $21^{\circ}$ dia de pós-operatório, no grupo tratado com AINH foi de 10,06, contra 11,54 do grupo com corticóide e, comparando-se a diferença de pressão do olho operado com o não operado, a variação foi de 0,66 para o grupo com AINH, contra 0,75 para o com corticóide. Se fosse considerado 1 ponto para cada cruz de hiperemia ou edema no $21^{\circ} \mathrm{PO}$, o grupo com AINH teria média 1,20 na hiperemia (contra 1,08 do grupo com corticóide) e 0,2 para edema, contra 0,08 no grupo usando corticóide. Em relação ao conforto, a nota média no $21^{\circ} \mathrm{PO}$ no grupo com AINH foi 9,26 e no com corticóide 9,70. Observandose estes dados vê-se que, quanto ao conforto, edema e hiperemia os pacientes com corticóide foram ligeiramente melhores, o inverso se dando em relação a PIO; no entanto, em nenhum dos casos a diferença entre os dois grupos foi expressiva.

Contudo, analisando-se os dados relacionados à hiperemia, 5/15 (33,3\%) pacientes do grupo tratado com AINH 
apresentaram $++/ 4$ de hiperemia no $21^{\circ}$ dia pós-operatório, tendo havido apenas 1 caso $(8,3 \%)$ no grupo com esteróide. Também se observou, entre os pacientes que usaram AINH, 3 casos de granuloma (20\%), ocorridos no lado em que foi feita a ressecção, não tendo sido encontrado nenhum no grupo tratado com corticóide.

A literatura menciona que os AINH são uma boa escolha para o controle da inflamação no pós-operatório de estrabismo. No entanto, estes trabalhos avaliaram predominantemente pacientes tratados com duplo recuo de retos horizontais. No presente estudo, o uso de AINH no pós-operatório de cirurgias de recuo-ressecção - procedimento que parece induzir maior resposta inflamatória - não se mostrou eficaz, uma vez que não controlou adequadamente a inflamação, apresentan-

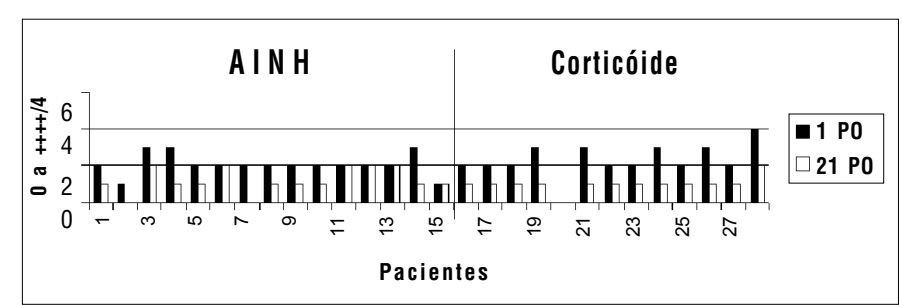

Gráfico 1 - Variação da hiperemia entre $01^{\circ}$ e $21^{\circ} \mathrm{PO}$, em cada paciente

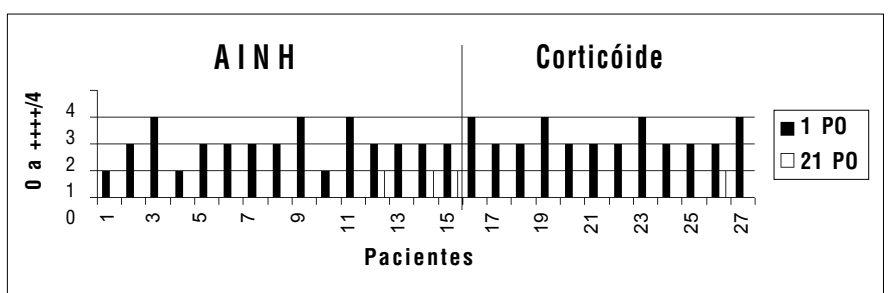

Gráfico 2 - Variação do edema entre $01^{\circ}$ e $21^{\circ} \mathrm{PO}$, em cada paciente

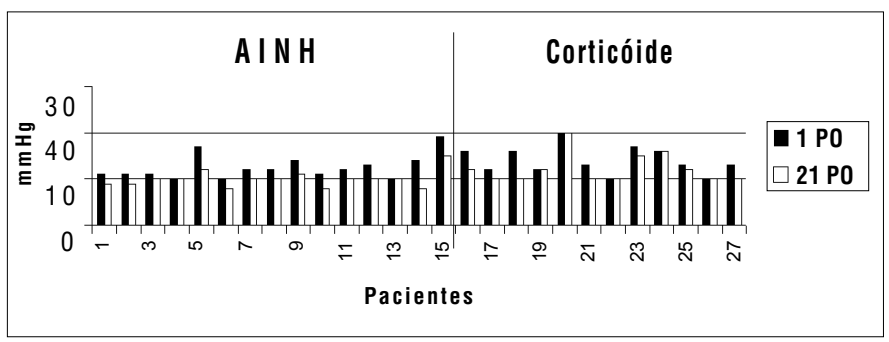

Gráfico 3 - Variação da PIO entre $01^{\circ}$ e $21^{\circ} \mathrm{PO}$, em cada paciente

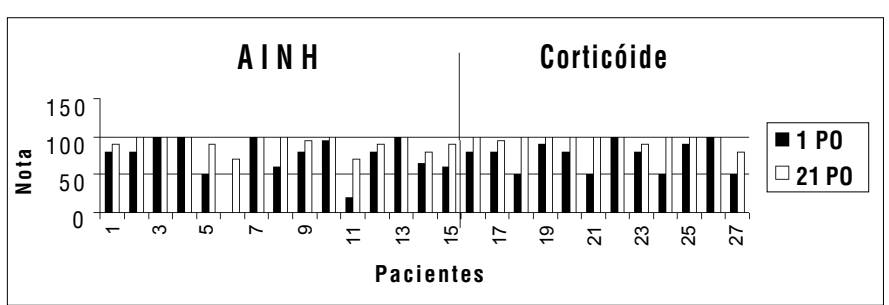

Gráfico 4 - Variação do conforto entre $01^{\circ}$ e $21^{\circ} \mathrm{PO}$, em cada paciente do, este grupo de pacientes, hiperemia conjuntival por maior tempo e alguns casos de formação de granuloma.

CONCLUSÃO

Este estudo sugere que o uso de AINH para o controle pósoperatório da inflamação que se segue a uma cirurgia de estrabismo, não parece ser tão eficaz quanto o uso de corticóide tópico, pelo menos nos casos de procedimentos cirúrgicos que induzem uma maior resposta inflamatória, como as cirurgias de recuo-ressecção, tão empregadas na prática cirúrgica.

ABSTRACT

Purpose: To compare the use of non-steroid anti-inflammatory drugs (NSAID) with steroids in the follow-up of strabismus surgery, regarding inflammation control. Methods: All patients underwent resection-recession surgery. Both groups used the same antibiotic eye-drop. One group used NSAID (ketorolac tromethamine- Acular ${ }^{\mathbb{}}$ ) and the other, prednisolone, $0.12 \%$ Pred Mild ${ }^{\circledR}$, for 21 days. They were examined with slit-lamp and ectoscopy to evaluate IOP (comparing with the fellow eye), edema, hyperemia and comfort. Results: Of a total of 23 patients, 15 were treated with NSAID and 12 with steroid. Regarding comfort, edema and IOP there was no important difference between the NSAID and steroid groups. However, when we analyzing hyperemia, there were $5(33.3 \%)$ patients in the NSAID group with $++/ 4$ of hyperemia at the $21^{\text {st }}$ postoperative day and only $1(8.3 \%)$ patient in the steroid group. There were also three granulomas $(20 \%)$ in the NSAID group and none in steroid-treated patients. Conclusion: For resectionrecession surgeries, procedures that induce a greater inflammatory response, the use of NSAID is not advisable.

Keywords: Inflammation/drug therapy; Strabismus/surgery; Anti-inflammatory agents, steroids/therapeutic use; Prednisolone topic/therapeutic use; Ketorolac tromethamine/therapeutic use

\section{REFERENCIAS}

1. Apt L, Voo I, Isenberg SJ. A randomized clinical trial of the nonsteroidal eyedrop diclofenac after strabismus surgery. Ophthalmology 1998;105:1448-54.

2. Hagan MC, Dinning WJ. Day case strabismus surgery without postoperative ocular medication. A masked randomised study. Eye 1987;1:581-4.

3. Kearns PP, Cullen JF. Fucithalmic, chloramphenicol or no treatment after squint surgery in children. A single blind randomised study. Acta Ophthalmol 1992;70:132-4.

4. Consoni Filho E, Vieira L. Inflamação ocular após cirurgia de estrabismo. Arq Inst Penido Burnier 1998;40:30-2. ano não lilacs

5. Roberts CW. Pretreatment with topical diclofenac sodium to decrease postoperative inflammation. Ophthalmol 1996;103:636-9.

6. Wright M, Butt Z, McIlwaine G, Fleck B. Comparison of the efficacy of diclofenac and betamethasone following strabismus surgery. Br J Ophthalmol 1997;81:299-301.

7. Ohji M, Kinoshita S, Ohmi E, Kuwayama Y. Marked intraocular pressure response to instillation of corticosteroids in children. Am J Ophthalmol 1991;112:450-4. 